\title{
SOBRE O DIREITO À COMUNICAÇÃO E O ACESSO DOS PRESOS À INTERNET
}

ABOUT PRISONERS' RIGHT TO COMMUNICATION AND ACCESS TO THE INTERNET

RESUMO: O contato do preso com o mundo exterior é previsto na Lei de Execução Penal, esse direito tem por objetivo buscar a proximidade da vida em cárcere com a vida em liberdade, visando a "ressocialização" do apenado (pois este, quando do seu retorno à sociedade, deve estar ciente dos acontecimentos familiares e das atualidades sociais). Mas, diante da atual realidade do sistema penitenciário brasileiro, nos deparamos com questões nas quais esse direito não existe ou quando está muito limitado. Encontramos, todavia, na tecnologia, mais precisamente na internet, uma forma de diminuir a limitação do direito à comunicação e à informação. Acompanhamos um ano de postagens no Facebook de três apenados gaúchos e visualizamos o uso corriqueiro desta rede social. Concluímos, então, que o acesso controlado à novos meios de comunicação garante respeito a esse direito dos presos, com economia, dignidade e segurança.

Palavras-chave: Direitos humanos. Direito do preso. Comunicação. Internet. Mundo exterior.
ABSTRACT: The contact of the prisoner with the outside world is envisaged in the Brazilian Law of Criminal Enforcement. This right pursues to seek the proximity of the life in prison to life in freedom, aiming at the "rehabilitation" of the prisoner (due the fact that the inmate, when able to return to society, should be aware of the events in family members' lifes and current social events). However, given the current reality of the Brazilian penitentiary system, we encounter situations in which this right does not exist or, when existing, is very limited. We have found, however, in technology, more precisely on the internet, a way to respect the right to communication and information. We followed a year of posts on Facebook of three prisoners from Rio Grande do Sul - Brazil and watched the everyday use of this social network. We infered that controlled access to the new media ensures respect of this prisioners' right, without high expenses and with dignity and safety.

Keywords: Human Rights. Right of the prisoner. Communication. Internet. The outside world.

\footnotetext{
${ }^{1}$ Professor do Centro Universitário Ritter dos Reis (UniRitter-RS).

${ }^{2}$ Advogado criminalista.
} 


\section{INTRODUÇãO}

No presente artigo, buscamos demonstrar a possibilidade de ampliação dos meios de contato dos presos com o mundo exterior, através da internet e do uso das redes sociais on line. Para tanto, reconhecendo as dificuldades de manter, legalmente, o direito à comunicação do preso com o mundo exterior, consideramos a realidade do sistema carcerário e as novidades tecnológicas e refletimos sobre o uso da internet (redes sociais) no cumprimento da pena em regime fechado.

É de conhecimento público a importância das formas de comunicação que a internet disponibiliza (Facebook e outros), inclusive a importância desses meios de comunicação. O Whatsapp foi tema de discussão recente no Supremo Tribunal Federal (ADPF no 403/SE), na qual se destaca a relevância da internet como instrumento democrático de acesso à informação e difusão de dados.

Assim, partimos da percepção de que, diante das dificuldades para utilizar os meios legais de contato com o mundo exterior, os apenados recorrem aos ilegais (internet e celular) para contatarem familiares e amigos. Buscamos refletir sobre o uso da internet no ambiente carcerário através de exemplos práticos da utilização do Facebook pelos apenados do sistema penitenciário do Rio Grande do Sul e demonstra que as restrições ao uso da internet acontecem sob a égide de medos infundados, ignorando as possibilidades de controle e restrições de uso presentes na tecnologia.

Destaquemos desde já que o direito do preso à comunicação com o mundo exterior é expresso tanto na legislação internacional quanto na nacional. As Regras Mínimas para Tratamento de Presos da ONU, bem como a nacional, asseguram o direito de contato do preso com o mundo exterior. O objetivo revelado na Lei de Execução Penal (LEP), Lei no 7.210/84, é de que a execução criminal se destina ao processo de reinserção social e apresenta o contato do preso com o exterior da prisão como importante meio para a busca desse fim. 
Nesse mesmo sentido, convém mencionar trecho da CPI do sistema carcerário de 2008, que afirma a importância da comunicação no âmbito carcerário (BRASIL, 2009, p. 264):

A questão da comunicação entre os presos, seus familiares ou terceiros deve ser enfrentada pelo Estado. Vivemos, na atualidade, na era da comunicação. Os presos perderam a sua liberdade e não a sua condição de cidadão. [...] Durante as diligências da $\mathrm{CPI}$, constatamos a felicidade dos presos aos quais foi permitido comunicarem-se com seus parentes. Garantir a comunicação por via telefônica ajuda a diminuir as tensões nos estabelecimentos penais, interrompe o uso de telefones clandestinos, evita-se a corrupção, as formas constrangedoras de ingresso dos aparelhos e contribui para o processo de ressocialização dos apenados.

Também deve ser considerado o fato de que, durante a execução da pena, o preso tem sua rede social limitada, restringida ao convívio na sociedade carcerária composta pelos demais apenados, agentes penitenciários e eventuais visitas de familiares, amigos e advogados. Nesse afastamento da sociedade livre, o apenado perde, ou no mínimo diminui, suas relações com amigos e familiares, não acompanhando as mudanças do mundo exterior, perdendo como referência as disposições sociais do mundo extramuros. Ainda, a rede social limitada existente na prisão obriga o apenado a adaptações culturais, vez que suas relações se restringem aos indivíduos presentes em seu cotidiano, à rotina do cárcere, aos costumes do sistema prisional.

Portanto, verifica-se a necessidade da abertura da prisão à sociedade, como importante meio de buscar o objetivo estipulado na lei. E, sendo assim, o acesso à internet pode ampliar a rede social do apenado, a fim de permitir a interação do preso com a sociedade livre, garantindo o uso da internet no cárcere de forma positiva e viável para permitir o acesso à vida extramuros.

Buscando resolver essa questão, utilizamos como técnicas de investigação a pesquisa bibliográfica em obras de referência nacionais e estrangeiras, bem como em documentos oficiais elaborados em nosso país e fora dele. Também realizamos um monitoramento do cotidiano de postagens no Facebook, durante o ano de 2014, de três apenados do sistema carcerário gaúcho, inclusive trocamos mensagens com um deles. 


\section{OS CONTATOS COM O MUNDO EXTERIOR}

O direito do preso ao contato com o exterior da prisão é de suma importância, tanto que o item no 92, das Regras Mínimas para Tratamento de Presos da ONU, prevê:

O preso não julgado será autorizado a informar imediatamente à sua família sobre sua detenção, e ser-lhe-ão dadas todas as facilidades razoáveis para comunicar-se com sua família e amigos e para receber as visitas deles, sujeito apenas às restrições e supervisão necessárias aos interesses da administração da justiça e à segurança e boa ordem do estabelecimento prisional.

A Lei de Execução Penal, em seu artigo 41, elenca direitos dos presos. Ela enumera direitos essenciais, que visam buscar a proximidade da vida no cárcere com a vida em liberdade, imaginando proporcionar os meios necessários e indispensáveis à "ressocialização" do apenado. O ponto que interessa, no contexto deste artigo, é o disposto no inciso XV, do artigo 41, que refere ao direito à comunicação, à informação e ao contato com o mundo exterior, nos seguintes termos: "Constituem direitos do preso: XV contato com o mundo exterior por meio de correspondência escrita, da leitura e de outros meios de informação que não comprometam a moral e os bons costumes".

Corroborando o mencionado inciso, a Resolução no 14, de 1994, do Conselho Nacional de Política Criminal e Penitenciária (CNPCP), em seu capítulo XI (Do contato com o mundo exterior), apresenta o direito do preso de estar informado dos acontecimentos familiares e das atualidades sociais (liberdade à informação):

Art. 33 - O preso estará autorizado a comunicar-se periodicamente, sob vigilância, com sua família, parentes, amigos ou instituições idôneas, por correspondência ou por meio de visitas. § 10. A correspondência do preso analfabeto pode ser, a seu pedido, lida e escrita por servidor ou alguém por ele indicado; § 2‥ 0 uso dos serviços de telecomunicações poderá ser autorizado pelo diretor do estabelecimento prisional.

Importante destacar que a LEP é datada de 11 de julho de 1984, época na qual não havia internet no Brasil. Diante disso, obviamente, não poderia abarcar o seu acesso como meio de comunicação do preso. Todavia, desde sua edição, não houve modificações, nem inclusões, no que diz respeito aos meios de contato do preso com o mundo exterior. Logo, uma interpretação extensiva dos meios de contato do apenado, previstos no incisivo XV, artigo 41 do LEP, parece ser possível e necessária, vez que ela menciona "meios de informação que não comprometam a moral e os bons costumes". Como, na atualidade, 
não se pode considerar apenas cartas e visitas como formas de contato com o exterior, devemos buscar outros meios idôneos e "morais".

Assim, considerando a realidade tecnológica do século XXI, podemos afirmar que a internet não é um meio que fere a moral ou os bons costumes, pelo contrário, é um meio de comunicação e informação amplamente difundido na sociedade, utilizado por cerca de 3 bilhões de pessoas no mundo (SANOU, 2014). Exemplo claro e atual da difusão da internet e seus meios de comunicação é projeto do Tribunal de Justiça do Rio Grande do Sul que utilizará o aplicativo de mensagens instantâneas WhatsApp para a realização de intimações das partes e procuradores em processos judiciais (CAVALHEIRO, 2016).

Portanto, é evidente que a internet é um veículo de comunicação difundido na sociedade e que seu uso costumeiro e progressivo atinge a maioria da população, estando incorporado em praticamente todos os aspectos da vida humana (MARCON, 2013). Em relação à possibilidade de afronta que a internet traria aos bons costumes e a moral, podemos repetir a explicação de Schmit (2007, p. 226), quando escreve sobre o uso de telefones celulares:

[...] Em termos abstratos, não parece possível sustentarmos que um telefone celular utilizado por um preso seja um meio de comunicação repulsivo à moral e aos bons costumes, até mesmo porque se trata de meio de comunicação amplamente difundido no meio social. [...]

Desta forma, é incorreto afirmar que a internet, como meio de comunicação, compromete a moral e os bons costumes, pois apenas o conteúdo (acessado ou enviado) pode ser considerado repulsivo. Sendo assim, se utilizada de maneira condizente com o objetivo exposto na Lei de Execução Penal, ou seja, com a finalidade de facilitar a readaptação do apenado, como meio eficiente de comunicação afetiva, para fins de informação, estudo etc., não estará contrariando o disposto na lei, pelo contrário, estará reforçando o objetivo desta.

Entendemos, dessa forma, não haver óbice ao uso da internet no sistema penitenciário, pois a própria legislação prevê o uso de meios de comunicação que não comprometam à moral e os bons costumes. 


\section{A REDE SOCIAL DO APENADO}

Como mencionado, na execução criminal se diz pretender a reinserção social do apenado; ao menos este é o objetivo declarado pela Lei, tendo em vista que o condenado, após sua prisão, voltará a viver em sociedade. Assim, o apenado, quando posto em liberdade deve estar ciente das atualidades sociais, ou seja, não deve ser excluído da realidade que encontrará quando do retorno. Daí a importância da relação com o mundo exterior, enquanto permanecer segregado. Podemos afirmar, assim, que a comunicação extramuros é uma das formas de preparação do condenado para sua futura saída da prisão. Convém, todavia, mencionar crítica realizada por Baratta $(1999$, p. 186) ao processo de "reeducação e reinserção":

O que se indicou em relação aos limites e aos processos contrários à reeducação, que são característicos do cárcere, se integra com uma dupla ordem de considerações, que toca ainda mais radicalmente a natureza contraditória da ideologia penal da reinserção. Estas considerações se referem à relação geral entre o cárcere e sociedade. Antes de tudo, esta relação é uma relação entre quem exclui (sociedade) e quem é excluído (preso). Toda técnica pedagógica de reinserção do detido choca contra a natureza mesma desta relação de exclusão. Não se pode, ao mesmo tempo, excluir e incluir.

Conforme explica Baratta (1999), há uma incongruência no processo de ressocialização do apenado, principalmente pelo fato de que o preso é retirado da sociedade para depois ser incluído, num processo totalmente contraditório. Partindo desse raciocino, entendemos que o afastamento do preso da sociedade não gera os benefícios que o Estado, em sua forma legal, busca. O contato efetivo do preso, com a sociedade, pode proporcionar a minimização dessa exclusão, e facilitar o objetivo da lei.

Baratta (1999) analisa as reformas penitenciárias italiana e alemã, dos anos de 1975 e 1976, mencionando como uma possível transformação qualitativa e funcional do sistema; a abertura à presença externa no cárcere, a maiores contatos entre presos e a sociedade externa, demonstrando, mais uma vez, o quão positivo é o contato do preso com o exterior da prisão.

Salientamos que, por conta deste fechamento, a "rede social" do apenado é limitada e restrita ao convívio com os demais apenados, agentes penitenciários e eventuais visitas de familiares, amigos e advogados. Sendo assim, tem-se por limitada, também, a 
informação real do mundo exterior, o que acarreta na dessocialização do apenado, eis que ele retorna a uma sociedade diferente da que foi retirada. Moretto explica $(2005$, p. 101):

Somente o contato com a sociedade e a tecnologia, ou seja, a redução máxima da ruptura espacial e temporal que é a prisão, é que poderia aumentar a possibilidade de trazer aquele que, se já não nasceu excluído ao tempo da sociedade atual, fora preso e tornado excluído para a sociedade dos incluídos. Afastando-o ao máximo de sua exclusão e retenção no passado, pois a pena de prisão, nos moldes atuais, mostra-se o inverso do discurso (re) que nos é vendido, poderíamos ter uma maior chance de reinserção.

Nesse sentido, vemos que a carência de informação e comunicação nas penitenciárias consolida barreiras para a ressocialização de quem lá vive, pois não permite a integração de informações básicas, cotidianas e corriqueiras da sociedade externa à prisão, restando seu vínculo restrito à sociedade carcerária. Goffman (1992, p. 24) resume esta situação na expressão "mortificação do eu", e declara:

Novato chega a estabelecimento com uma concepção de si mesmo que se tornou possível por algumas disposições sociais estáveis no seu mundo doméstico. Ao entrar, é imediatamente despido de apoio dado por tais disposições. Na linguagem exata de algumas de nossas mais antigas instituições totais, começa uma série de rebaixamentos, degradações, humilhações e profanações do eu. 0 seu eu é sistematicamente, embora muitas vezes não intencionalmente, mortificado. Começa a passar por algumas mudanças radicais em sua carreira moral, uma carreira composta pelas progressivas mudanças que ocorrem nas crenças que têm a seu respeito e a respeito dos outros que são significativos para ele.

A "rede social" limitada do preso influencia de forma negativa no seu comportamento. Suas relações se restringem aos indivíduos que estão presentes no seu dia-a-dia, limitando-o à rotina e aos costumes do sistema prisional. As experiências carcerárias reconstroem os valores, atitudes e os costumes, em um processo denominado por Clemmer (1966, p.298-299) de "prisonização":

[...] o termo assimilação descreve processo lento, gradual, mais ou menos inconsciente, durante o qual uma pessoa aprende o suficiente da cultura de uma unidade social, em que ela é colocada, para se fazer característica dela. Enquanto nós continuarmos a utilizar este significado geral, reconhecemos que, no sentido estrito, assimilação não é o termo correto. Então, assim como nós usamos o termo americanização para descrever um maior ou menor grau de integração do imigrante no esquema de vida americano, podemos usar o termo prisonização para indicar a aceitação em maior ou menor grau das práticas populares, costumes, condutas, e cultura geral da penitenciária. Prisonização é semelhante à assimilação, e seu significado se tornará mais claro à medida que avançarmos. 
Mesmo após a saída do sistema prisional, essa cultura (esses hábitos), acompanha os presos e traz consequências, gerando dificuldades para se adaptarem à nova realidade social (e pessoal). Os valores e os costumes impostos ao preso, em razão da sua "rede social" carcerária, geram enormes dificuldades de adaptação em sua reinserção na sociedade livre, pois divergem das condutas que encontrarão no mundo externo à prisão. Complementa Zaffaroni (1991, p. 136), "o efeito da prisão, que se denomina prisonização, sem dúvida é deteriorante e submerge a pessoa numa "cultura de cadeia", distinta da vida do adulto em liberdade".

A limitada "rede social" do apenado o estigmatiza e o desabitua, criando uma alienação carcerária. Seu novo ambiente social é completamente diferente do que ele teve e encontrará fora do cárcere. Na prisão, ele é obrigado a se "educar" e organizar conforme sua "rede social". Afirma Hassemer (2005, p. 378):

As penas privativas de liberdade estigmatizam e desabituam (entwöhnt). Elas mantêm os presos isolados só em um espaço, mas também socialmente. "Educação para a liberdade através da privação da liberdade" não é apenas o título bem elaborado de uma publicação, mas expressa o evidente paradoxo das modernas teorias da pena. $O$ preso é privado amplamente dos seus contatos íntimos e sociais. Ele é levado a um ambiente social que o mantém afastado dos problemas, nos quais ele fracassou fora do estabelecimento (que lhe criavam também novos problemas). Ele desaprende as técnicas sociais de convívio e de aprovação (e inclusive aprende outras). E ao término do tempo da pena ele volta, desabituado e estigmatizado a um mundo que, fora dos muros da prisão, se desenvolveu de acordo com as suas próprias leis.

O sistema carcerário não prepara o apenado para a reinserção social, pois ao limitar o acesso ao mundo exterior, mantém o encarcerado estagnado no passado, dificultando que siga no tempo da sociedade. Nesse sentido, Moretto (2005, p. 98) explica:

Vê-se que o sistema carcerário tem como um de seus objetivos, da forma com que é aplicado, não a preparação do condenado para um devir, mas a remomerização do fato que levou-o até aquela posição, ou seja, trata-se de uma máquina de estagnação temporal no passado, mantendo-o encarcerado num tempo do qual ele jamais sairá, tanto que Ana Massuti, trabalha com o pensamento platônico, afirma que a prisão implica um total isolamento do delinqüente do resto da comunidade de pessoas livres, ou seja, a prisão é o grau máximo da exclusão, tanto que nem com a morte cessa.

Não outra é a perspectiva apresentada por Lévi Strauss (1996, p. 366): 
[...] Penso em nossos costumes judiciários e penitenciários. Ao estudá-los de fora, ficaríamos tentados a contrapor dois tipos de sociedades: as que praticam a antropofagia, isto é, que enxergam na absorção de certos indivíduos detentores de forças tremendas o único meio de neutralizá-las, e até de se beneficiarem delas; e as que, como a nossa, adotam o que se poderia chamar de antropemia (do grego emein, "vomitar"). Colocadas diante do mesmo problema, elas escolheram a solução inversa, que consiste em expulsar esses seres tremendos para fora do corpo social, mantendo-os temporária ou definitivamente isolados, sem contato com a humanidade, em estabelecimentos destinados a este fim. $\mathrm{Na}$ maioria das sociedades que chamamos de primitivas, tal costume inspiraria um profundo horror; em seu entender, isso nos marcaria com a mesma barbárie que seríamos tentados a imputar-lhes por causa de seus costumes simétricos.

Baratta (1991, p. 254) afirma a necessidade de abertura da prisão à sociedade e menciona a comunicação do preso com a sociedade:

Ressaltamos a necessidade da opção pela abertura da prisão à sociedade e, reciprocamente, da sociedade à prisão. Um dos elementos mais negativos das instituições carcerária, de fato, é o isolamento do microcosmo prisional do macrocosmo social, simbolizado pelos muros e grades. Até que não sejam derrubados, pelo menos simbolicamente, as chances de "ressocialização" do sentenciado continuarão diminutas. Não se pode segregar pessoas e, ao mesmo tempo, pretender a sua reintegração. Todavia, a questão é mais ampla e se relaciona com a concepção de "reintegração social", conceito que decididamente preferimos aos de "ressocialização" e "tratamento". "Tratamento" e "ressocialização" pressupõem uma postura passiva do detento e ativa das instituições: são heranças anacrônicas da velha criminologia positivista que tinha o condenado como um indivíduo anormal e inferior que precisava ser (re)adaptado à sociedade, considerando acriticamente esta como "boa" e aquele como "mau". Já o entendimento da reintegração social requer a abertura de um processo de comunicação e interação entre a prisão e a sociedade, no qual os cidadãos reclusos se reconheçam na sociedade e esta, por sua vez, se reconheça na prisão.

Deste modo, a comunicação do preso com indivíduos que não vivem no cárcere amplia a denominada "rede social", permitindo a troca de informação entre o preso e as pessoas que estão fora do sistema carcerário, podendo esse contato ser realizado com auxilio da internet.

\section{O DIREITO DE VISITA}

O recebimento de pessoas (familiares e amigos) é a principal forma de garantia de contato do preso com o mundo externo à prisão. Fundamental para a mantença da paz na 
prisão (MORAES, 2005, p. 251), surge como a única relação pessoal direta do preso com seus familiares e amigos.

Assim como os outros direitos relacionados à comunicação, a visita auxilia o apenado na vivência dentro do sistema carcerário, bem como no seu retorno à sociedade livre. (Anonimizado) revelam:

Cabe ainda destacar que visitantes e objetos por eles trazidos que amenizam problemas maiores no PCPA, nas demais prisões gaúchas e brasileiras. Eles ajudam a suprir a falta do Estado na garantia aos presos de objetos matérias dos presos em regime fechado, levando roupas e objetos pessoais, obrigação da qual, com a conivência do Poder Judiciário, que não intervém, o Executivo abriu mão.

Ocorre que o direito à visita não é uma realidade para muitos apenados. Em nosso sistema carcerário é frequente que presos deixem de receber visitas, sendo o principal motivo a distância das penitenciárias e a falta de condições financeiras dos familiares para custearem os deslocamentos. A CPI do Sistema Carcerário salientou essa problemática (BRASIL, 2009, p. 259), afirmando que a distância do preso de seu meio social afeta e dificulta o processo de ressocialização.

Exemplos desse problema são recorrentes nas penitenciárias federais, localizadas nas cidades de Catanduvas (Paraná), Campo Grande (Mato Grosso do Sul), Mossoró (Rio Grande do Norte) e Porto Velho (Rondônia). Destacamos que o sistema federal é de exceção, que existe para retirar os presos dos sistemas estaduais, isolar líderes de facções criminosas, e por isso se localiza distante dos grandes centros urbanos do país. Conforme dados apresentados no relatório de pesquisa do perfil sócio criminal dos internos da Penitenciária Federal de Catanduvas (MINISTÉRIO DA JUSTIÇA, 2014a), a maioria dos internos são provenientes dos estados de Pernambuco, Espírito Santo, Rondônia e Pará e o relatório de pesquisa do perfil sócio criminal dos internos da Penitenciária Federal de Campo Grande (MINISTÉRIO DA JUSTIÇA, 2014b) informa que a maioria dos internos são provenientes dos estados da Paraíba, Sergipe, Amazonas e Acre, além de estrangeiros (italianos, colombianos, chilenos, bolivianos, entre outros).

Assim, podemos visualizar a problemática enfrentada pelos familiares dos apenados destas unidades e entender o porquê do não recebimento das visitas. Segundo dados levantados no Projeto Visita Virtual, nessas penitenciárias, mais da metade dos apenados 
não recebem visita social de amigos ou familiares, inclusive foi identificado um apenado que não recebia visita há 11 anos. Defensores públicos federais, Lacerda e Franco (2011), destacam que a falta de visita "[...] dificulta a manutenção dos laços familiares que são essenciais para reabilitação das pessoas que cumprem uma pena privativa de liberdade e sua futura reinserção do espaço social". E complementam:

[...] Pode-se constatar que mesmo antes de serem transferidos para o SPF, 9 (nove) $17,30 \%$ não estabeleciam contato com os familiares há pelo menos um ano, sendo que o que fazia mais tempo estava sem falar com a família há 11 (onze) anos. Os 43 (quarenta e três) restantes, 82,69\% estavam sem contato com a família desde que foram incluídos nesta unidade. [...] A falta de condições materiais da família foi colocada por 48 (quarenta e oito), ou seja, 92,3\% dos entrevistados como a principal causa de não receberem visitas presenciais, demonstrando que os presos sofrem de uma dupla exclusão: a anterior ao encarceramento, pois antes da prisão já não eram incluídos socialmente e a exclusão dentro do próprio cárcere, que Ihes tira a possibilidade de convívio com sua família. [...]

A questão apresentada não é uma realidade apenas nas penitenciárias federais, o mesmo problema é visualizado em penitenciárias estaduais, onde a distância e a falta de condições financeira inviabilizam a manutenção do direito à visita. Diante dessa realidade, há geração de uma dupla punição ao apenado, ante a perda da liberdade e do contato com os familiares.

Ressalta-se que a visita normalmente é realizada por familiares, em especial mulheres (mães e esposas), dificilmente por amigos. No Presídio Central de Porto Alegre, por exemplo, de 7.192 visitantes do sexo feminino, apenas 93 são cadastradas como amigas dos apenados, e dentre os 2.424 homens, apenas 10 se declaram amigos (ANONIMIZADO).

Outro meio de contato do preso com o mundo exterior é a correspondência. Ela, todavia, tanto demonstra deficiências que caiu em desuso. A carta não atinge os objetivos almejados (há o analfabetismo, o custo do selo, a demora e mesmo o fato de familiares viverem em ruas sem nome oficial, o que significa não serem alcançados pela distribuição de cartas da Empresa Brasileira de Correios e Telégrafos).

Isso foi comprovado em junho de 2014, quando realizamos coleta de dados no Presídio Central de Porto Alegre. Verificamos na oportunidade que no PCPA encontravam- 
se 4.227 presos e, em três dias de distribuição de correspondência (seis, nove e 12 de junho), receberam tão somente 87 cartas, ou seja, 0,02 cartas por apenado. Corroborando tal constatação, (Anonimizado) refere à chegada da correspondência: “Às 15h27 chega o correio. São oito cartas, sete da Penitenciária Feminina de Guaíba e uma da Defensoria Pública. Os presos assinam em livro de controle o recebimento". Observa-se que entre os detidos no pavilhão "B", apenas oito receberam carta naquele dia, de órgãos públicos e de mulheres presas.

Desta forma, demonstramos a ineficácia dos principais meios de contato do preso com o mundo exterior e verificamos a necessidade de ampliação desses meios, com o intuito de dar efetividade ao direito de contato estabelecido na lei. Acreditamos que o acesso à internet pode auxiliar na garantia de tal direito.

\section{A GESTÃO DE CRIMES PELA INTERNET}

Quando se fala em acesso à internet no sistema carcerário, logo surge a questão do crime gestado no interior dos presídios. Esse é o principal argumento contrário à utilização da internet pelo preso. Inclusive, existe o Projeto de Lei do Senado no 586, de 2011, de autoria do senador Paulo Bauer, para alterar a Lei de Execuções Penais e determinar como falta grave o acesso a endereço eletrônico, a programa de conversação ou a qualquer rede social de comunicação entre computadores, por parte do condenado à pena privativa de liberdade. A justificativa para tal projeto está na alegação de que "[...] muitos 'comandantes' do crime organizado continuam comandando suas organizações criminosas de dentro dos presídios com o uso de smartphones" (ALTAFIN, 2014).

Essa ideia, porém, não se sustenta. O preso que realmente deseje "mandar" ou "gestar" a realização de um crime, pode fazê-lo através das visitas, correspondências e não por intermédio da internet, cujo acesso, destacamos, pode ser tão ou mais facilmente restringido, interceptado e controlado do que as demais formas de contato com o mundo exterior.

Existe uma gama de métodos de controle do uso da internet, como limitações de locais de navegação, seriação de palavras proibidas, monitoramento simultâneo, classificação de sítios virtuais, monitoramento de históricos, entre outros. Diante dessa 
gama de sistemas de segurança e controle de informação e ação na internet, revela-se a possibilidade de alcançar um compromisso equilibrado de seu uso, fortalecendo, inclusive, a manutenção da estabilidade do sistema prisional.

Tempo para planejar fuga ou delitos o apenado possui. E os modos de exigir sua execução também: pode ser por telefone, pessoalmente, com apoio de um visitante ou de um operador jurídico (advogado, agente penitenciário, juiz ou promotor), por meio de correspondência codificada ou até por meio de rede social. (Anonimizado) alertam:

Embora, com o passar do tempo, permaneça o fato de que a imensa maioria dos visitantes, em uma penitenciária masculina, seja do sexo feminino, também aconteceram modificações. As cartas, por exemplo, desapareceram. Isso se relaciona, de forma clara, com a popularização do uso de telefones celulares. A vigilância constante para evitar que eles ingressem parece ineficaz. De toda forma, por parte da classe dirigente, há convicção de que sua utilização ocorre, majoritariamente, em substituição às cartas para familiares. Ordens para administração de "negócios" podem acontecer, afirmam, por meio de contato pessoal com advogados e, em especial, com as próprias visitas, que podem levar e trazer instruções.

Mas, sendo tantos os meios, alguém consideraria que se proíbam todos? Acreditamos que não. Neste sentido, lição de Schmidt (2007, p. 226):

Contudo, o principal argumento no sentido da ilegalidade da proibição de telefones celulares (que invalidaria, inclusive, uma eventual lei federal que estipulasse eventual proibição) refere-se à liberdade de comunicação prevista no inciso IX do art. 5o da Constituição, ou seja, não é o fato de, em algumas situações, o uso de telefones celulares ser um mecanismo eficiente de provocação de rebeliões que se privará, de uma maneira geral, o preso de comunicar-se com outras pessoas. Diga-se de passagem, pode muito bem o telefone celular servir de aproximação entre a vida carcerária e o meio social para o qual deseja o Estado que o preso retorne devidamente "adaptado". A prosperar esta argumentação, nem mesmo o direito a corresponder-se, via postal, poderia prevalecer.

Resta informar que a polícia militar do Rio Grande do Sul, responsável pelo controle externo e interno do maior presidio do Estado, e um dos maiores do Brasil, informa e mostra aos pesquisadores que visitam a casa os chips apreendidos. E as mensagens trocadas com o exterior são todas para familiares e amigos; nenhuma trata de "encomenda" de crime. Claro que essa é uma amostra e há quem o utilize para tal (e os chips são então remetidos para investigação), mas isso demonstra que a maioria dos 
presos não gesta delitos e necessita de canais de comunicação com as pessoas de fora dos muros.

Cabe salientar pesquisa realiza por (Anonimizado), na Penitenciária Feminina Madre Pelletier, na qual se desvela o uso prático do celular por uma apenada:

[...] uma das presas entrevistadas lembra-se de situação na qual estava com grande dor de cabeça e pediu atendimento médico. A AP disse, nas palavras da detenta: "Ó, a senhora nunca incomodou na revista, a senhora não incomoda ninguém, se todas presa fosse que nem a senhora era bom". Então obteve a consulta e o médico recomendou uma determinada medicação, naquele momento indisponível dentro da prisão. A presa ligou, de sua cela, com celular ilegal, para a filha e pediu para trazê-la. E pensou como explicar a situação para a AP. Decidiu então mostrar a receita médica e pediu para fazer uma ligação. "Ó, eu deixo a senhora fazer uma ligação ali, ó, a senhora pode fazer ligação pra ela porque é por doença, mas isso aqui a gente não pode fazer". Ela ligou e quando a filha chegou com a medicação ninguém desconfiou de nada. Normalmente, são as assistentes sociais ou, até mesmo, as agentes penitenciárias que entram em contato com a família das detentas para solicitar a compra de medicamentos que não são disponibilizados pela enfermaria da penitenciária ou não podem ser comprados pelo administrativo.

Portanto, essa conclusão, de caráter subjetivo, de que o preso com acesso à informação, comunicação, seja por meio da internet ou do celular, irá "gestar" ou "mandar" a execução de crimes não se sustenta. Esse pensamento não pode ser direcionado para toda comunidade carcerária, pois restringe o direito de comunicação expressamente previsto em lei.

Seria sustentar, por exemplo, considerando os quase 4.500 presos do Presídio Central de Porto Alegre, caso o acesso à internet fosse liberado, que todos cometeriam crimes ou que todos não cometeriam. Da mesma forma que na vida das pessoas livres, alguns comentem crimes e outros não, provavelmente apenados iriam utilizar de forma equivocada, mas indevido se mostra generalizar de forma negativa, privando o apenado de seu direito à comunicação. Os benefícios do acesso à internet suplantam os malefícios que sua liberação possa trazer. Nesse sentido, convém mencionar (BRASIL, CPI, 2009, p. 264):

A grande maioria dos presos é constituída de pessoas em condições de recuperação. Uma minoria vive do crime e para o crime. Desta forma, não se deve proibir o direito ao telefone público, sob alegação de que todos os potenciais usuários irão utilizá-lo para fins ilícitos. A falta de telefone público nos estabelecimentos provoca o uso clandestino de telefones celulares, estimulando a corrupção nas suas mais variadas formas. [...] 
Além do mais, essa previsibilidade de cometimento de crime, utilizada como argumento contrário ao uso da internet, pode ser considerada como um bis in idem, pois se pune o apenado pelo crime que cometeu, através da perda da liberdade (ir e vir) e, também, pela possibilidade de comedimento de crime (futuro) pelo uso da comunicação (internet/celular). É forma de puni-lo com limitação de direito, previsto (de contato com o mundo exterior), tendo como argumento uma possibilidade de cometimento futuro e incerto de um crime.

Sendo assim, pensamos que não será a internet ou o celular que fará com que o preso "comande" o crime do interior das penitenciárias. A minoria de presos que, mesmo no cárcere, continua a perfazer o ilícito, independente da internet. É inegável que ela pode facilitar a realização de ilícitos, do mesmo modo que a visita e a correspondência, mas ninguém propõe a proibição destes direitos, pois estes possuem sua importância demonstrada e os benefícios gerados por eles vão muito além de suas ínfimas consequências negativas.

Entendemos que os benefícios podem ser ampliados e melhorados, com a utilização da internet. Limitar o acesso do preso ao direito à comunicação, com base em presunções, confrontando riscos óbvios, ignorando as importantes vantagens que o acesso à internet oportuniza, não se mostra satisfatório.

\section{A IMPLEMENTAÇÃO DO ACESSO À INTERNET}

Com o desuso da correspondência e com as dificuldades apresentadas para a realização de visitas nos estabelecimentos prisionais, verificamos a utilização da internet como meio de comunicação em penitenciárias, dentro e fora do Brasil. Coyle (2004, p. 122) salienta que "algumas administrações penitenciárias permitem que os presos tenham acesso a outras formas de comunicação, inclusive correio eletrônico. Essa prática é permitida, por exemplo, na penitenciária Tihar, de Nova Deli. Para alguns presos, principalmente estrangeiros, esse poderá ser o único método confiável e barato de manterem contato com suas famílias".

Diante da evolução da informática, dos sistemas de segurança e controle de informação e ação na rede virtual, revelou-se a possibilidade de alcançar um compromisso 
equilibrado de seu acesso por parte dos presos, fortalecendo a manutenção da estabilidade social. Nos Estados Unidos, o sistema Trulincs, utilizado em uma prisão federal, oportuniza, através de mensagens eletrônicas, o contato entre presos e seus familiares. Esse sistema funciona da seguinte forma:

Os presos só podem enviar e receber mensagens eletrônicas de pessoas físicas em sua lista de contatos aprovado. Esta é a forma como o processo se inicia:

1. Solicitações dos presos para a troca de mensagens eletrônicas com uma pessoa na comunidade. Eles colocam a pessoa em sua lista de contatos, que devem ser aprovados pela equipe.

2. Após o contato for aprovado, uma mensagem automática será enviada para essa pessoa perguntando se eles aceitam a futura comunicação eletrônica com o preso ou se quer bloqueá-lo.

3. Se o respectivo contato aceitar as mensagens, o preso será, então, capaz de enviar mensagens eletrônicas para esse indivíduo. (FEDERAL Bureau of Prisons, 2017)

Também nos Estados Unidos, tendo em vista o desuso do hábito de escrever cartas, foi criada uma rede chamada WRITE a prisoner (2017), que visa resgatar o contato do preso com o mundo exterior através do uso da correspondência. WRITE a prisoner permite que pessoas de todo mundo visualizem perfis dos detentos através de um sítio eletrônico e os selecionem para troca de correspondências. Ainda importa ressaltar que, na Inglaterra, relatório do HM Chief Inspector of Prison (2016, p. 21) afirma:

A possibilidade de os prisioneiros realizarem chamadas telefônicas e escreverem cartas é de suma importância para ajudá-los a manter os laços familiares e acessar formas de ajuda e apoio. São necessárias salvaguardas no entanto, para evitar o uso inadequado de telefones e cartas, como entrar em contato e assediar vítimas ou testemunhas. [...]

O relatório esclarece que, para terem direito de usar o telefone, os prisioneiros precisam informar com antecedência o número e indicar se é confidencial (consideram-se como tais os telefones de advogados, membros do parlamento e de outras organizações). Toda ligação para número não confidencial pode ser monitorada.

No Canadá, Mandy Hiscocks, que ficou presa por quase 11 meses, em decorrência de ativismo político, criou um blog (http://boredbutnotbroken.tao.ca) para se comunicar enquanto estava na penitenciária. Com isso, ela afirmava pretender "[...] tirar um pouco da pressão de cima de meus amigos e familiares". No blog, Hiscocks explica como as pessoas podem visitá-la ou falar com ela por telefone. Esclarece não poder receber ligações 
telefônicas, mas poder realizá-las - pede então que enviem o número por e-mail, que ela irá telefonar, promete também responder a todas as cartas.

No Brasil, a Defensoria Pública da União, em parceria com o Departamento Penitenciário Nacional, desenvolve o Projeto Visita Virtual, com o objetivo de garantir o direito de visita aos presos das penitenciárias federais, através de transmissão de imagens pela internet.

O projeto foi desenvolvido em decorrência da citada dificuldade encontrada pelos familiares para deslocamento aos presídios federais e destaca a família como um importante pilar para a reintegração do preso ao convívio social. Conforme explicam Lacerda e Franco (2011):

[...] verificou-se que mais da metade dos presos não recebia visita social dos familiares ou amigos, devido à distância que se encontravam seus visitantes e a falta de condições financeiras para o deslocamento. Tal fato dificulta a manutenção dos laços familiares que são essenciais para reabilitação das pessoas que cumprem uma pena privativa de liberdade e sua futura reinserção do espaço social. Assim, em consonância com o direito da pessoa humana em manter o contato com seus familiares, o referido projeto foi planejado e executado, com intuito de se garantir a manutenção dos laços familiares e sociais dos presos, objetivando aproximar estas pessoas, facilitando a sua reinserção no meio social.

Salientam ainda:

[...] A razão era simples, falta de condições financeiras para o deslocamento do parente ou amigo. A situação trazia grande mal estar a estes internos, pois não consideravam justo o afastamento de suas famílias. Sentiam-se duplamente punidos pela sociedade, com a perda da liberdade e com a perda de contato com os seus familiares. Havia conformação com a perda da liberdade, mas a perda do direito de contato com os familiares causava revolta. Apesar da penitenciária garantir o direito de visita do cônjuge, companheiro, familiar ou amigo do preso, na prática, por razões econômicas, esta não ocorria com a metade dos internos.

Os projetos mencionados utilizam a internet de forma positiva para o acesso à comunicação extramuros, possibilitando a manutenção dos vínculos afetivos dos presidiários com familiares e pessoas fora do cárcere.

\section{A UTILIZAÇÃO DO FACEBOOK}

O Facebook é a rede social na internet mais utilizada no mundo e proporciona que as pessoas se comuniquem de forma rápida, fácil e abrangente; oferece a possibilidade de 
debates abertos e plurais (ou sectários e discriminatórios), auxilia na criação e na difusão da informação, além de fortalecer laços sociais com amigos e familiares.

Não é novidade o uso das redes sociais por apenados, principalmente o Facebook, dentro do sistema carcerário brasileiro. São inúmeras reportagens que noticiam (e denunciam) esse uso. Elas normalmente expõem presos que postam fotos e mensagens para familiares e amigos nas redes sociais, debochando do descontrole das autoridades no âmbito prisional.

No monitoramento de postagens de presos no Facebook, verificamos uma rotina de postagens comum a tantos jovens, não diferenciando do uso de outros integrantes desta rede social. A observação contraria a ideia negativa do uso da rede social; visualizamos a inexistência de incitação a pratica de crimes e observamos demonstrações de afeto, afirmações de saudades, conversas comuns com familiares e brincadeiras entre amigos.

Notamos, durante o período de monitoramento, que as publicações mais frequentes são aquelas que demonstram o sentimento da saudade. Tanto os apenados, quanto amigos e familiares, fizeram diversas referencias e expressaram este sentimento em suas publicações. Assim, ao acompanhar a utilização do Facebook pelos apenados, ficou evidente que as publicações são uma forma de conforto no cumprimento da pena, contribuindo de forma direta na pena, pois conforme relato de um dos apenados, é através destas relações que advém auxílio para o passar do tempo dentro do cárcere. Segue diálogo virtual que tivemos com um dos apenados:

\footnotetext{
Apenado 01: - A até q não é tao pesada minha cadeia embolado com pessol vindo e sempre com u corizinho e uma nave pra dar uma banda na internet e pa. Não é tão pesado. Mas to loco $\mathrm{p}$ hi embora d uma vez kk

Pesquisador: - heheh está certo, o Facebook ajuda "afu" né?!

Apenado 01: - Ba disvirtua a mente nem vejo passa os dias
}

Nesse trecho da conversa ele demonstra a importância do contato com o mundo exterior, relata que em decorrência da visita ("pessol vindo"), da visita íntima ("corizinho") e de um aparelho para navegar pela internet ("uma nave pra da uma banda na internet"), o cumprimento da pena fica mais confortável. Ressalta a vontade de ir embora e, por fim, salienta que o Facebook "desvirtua" a mente, pois ajuda no passar dos dias, auxiliando no lapso temporal da pena. 
Outro apenado postou: "bah q lugar do inferno preso e sem um cartão pra liga pos amigos meu pa sai um poko desse lugar do inferno se alguém quise por um pra mim agradeço $858782 X X^{\prime \prime}$. O inicio da frase demonstra o auxílio que o contato com o mundo exterior traz ao apenado, pois, conforme apontado por ele, falar com amigos liberta do ambiente carcerário, ao menos temporariamente, auxiliando na diminuição do sentimento de saudade. Chama atenção também que durante o período das postagens os apenados não extorquiam valores para auxilio ao uso da internet (via celular), conforme se pode observar da postagem mencionada. O preso pede e agradece caso seja possível enviar créditos ao celular dele. Em outra postagem, assim fez o pedido: "alguém quer.me botar um cartão to sem nada de credito 858782.. por favore".

Ainda, anteriormente, neste artigo, referimos a distância das penitenciarias como um problema para o exercício do direito à visita e para o direito a comunicação com o mundo externo a prisão. Durante a pesquisa, um dos apenados postou no Facebook que estava preso em Osório, cidade distante 102 quilômetros de Porto Alegre, e que havia pedido transferência para cumprimento da pena próximo aos seus familiares: "ho gloria senhor, finalmente foi dada a entrada dos meus papeis tomara q cante logo a minha transferencia para porto-alegre so por voltar pa capital [...]".

Diante desta postagem podemos observar que a barreira da distância de seu lugar de origem é uma realidade e que a internet/celular torna-se o único meio de comunicação com o mundo externo à prisão de que esse apenado dispõe, considerando a distância da prisão até a capital.

O monitoramento das postagens dos três apenados demonstra que a utilização do Facebook por eles é comum e ordinária. As postagens limitam-se a mensagens de texto (trechos de músicas, desabafos, expressões de sentimentos), postagens de fotos e conversas entre familiares e amigos. Reafirmamos que não foram visualizadas postagens de incitação ou apologia ao crime, nem de extorsão; no máximo visualizamos pedidos, sempre na forma de apelo ou solicitação.

De forma geral, o contato com o mundo exterior, através do Facebook/celular, foi positiva. A impressão apresentada é de inclusão. Através das postagens, o contato com os familiares e amigos restou mantido, amenizando a exclusão do apenado da sociedade 
livre. O uso da rede social auxiliou tanto o apenado, que viu seu direito ao contato com o mundo exterior garantido, como a instituição carcerária, pois permitiu manter a estabilidade do sistema.

\section{CONCLUSÃO}

O direito do preso à comunicação com o mundo exterior está expresso na legislação brasileira, na Lei de Execução Penal. Ela é permitida quando não compromete a moral e os bons costumes. Diante disso, e da necessidade de comunicação de todo ser humano, entendemos que a interpretação do direito de acesso aos meios de comunicações deve ser extensiva, para comportar a atual realidade social e tecnológica; afinal, para buscar corroborar a finalidade da lei, a interpretação necessita estabelecer um raciocínio lógico e humanista, indo além do explícito no texto legal.

Como mencionado, a LEP existe há 33 anos e os meios de comunicação se modificaram radicalmente. Computadores e telefones celulares tornaram-se instrumentos ao alcance de todos, sem distinção de idade e classes sociais. Hoje, diferente de três décadas atrás, a internet faz parte do cotidiano de vida das pessoas de todo o mundo e é, sem dúvida, a principal ferramenta de comunicação disponível.

Devemos lembrar que no contexto apresentado pela Lei, a função da prisão não se resume, apenas, ao encarceramento e ao afastamento, por completo, entre o preso e o mundo exterior. Deve a prisão, declara a LEP, proporcionar a aproximação necessária do preso com a sociedade livre, a fim de alcançar sua reabilitação e reinserção social. Não diverso é o entendimento demostrado da legislação e doutrina internacional.

Demonstramos, no artigo, a importância da comunicação com o exterior da prisão para o preso. Constatamos, através de contato direto com um apenado, quão significativo é tal direito para o cumprimento da pena. Visualizamos postagens de apenados no Facebook, durante um ano, e observamos o uso corriqueiro, comum, não se diferenciando de postagens de pessoas em liberdade.

Assim, considerando que a limitada rede social do apenado dentro da prisão acarreta sequelas que vão influenciar sua vida durante e após o encarceramento, o 
contato com o exterior auxilia a minimizar os efeitos da prisonização, bem como prepara o apenado para sua proclamada reinserção na sociedade.

Lembremos que os meios de contato com o exterior da prisão apresentam graves deficiências e que a visita, o principal meio de contato, muitas vezes não é realizada por falta de condição financeira dos parentes dos presos, pela distância das penitenciárias. Além disso, a correspondência caiu em desuso; logo considerando que a comunicação é essencial para as relações humanas e direito garantido aos apenados, sendo uma ferramenta fundamental para manter a estabilidade do sistema prisional, demonstramos a necessidade de expansão dos meios para comunicação do preso.

$\mathrm{E}$, sendo assim, devemos pensar que toda e qualquer forma de auxilio que venha a tornar o cumprimento da pena de prisão menos danoso, mais humano e digno, deve ser implementada. A internet pode ser utilizada para tal fim, com os devidos controles de acesso. Ela contribui para a proximidade e manutenção dos laços afetivos entre familiares e amigos, além de proporcionar informações atuais do mundo fora do cárcere.

무무

\section{REFERÊNCIAS}

ALTAFIN, lara Guimarães. Comissão aprova medida para coibir acesso de preso à internet. Disponível em: http://www12.senado.gov.br/noticias/materias/2012/10/17/comissaoaprova-medida-para-coibir-acesso-de-preso-a-internet. Acesso em: 23 set. 2014.

BARATTA, Alessandro. Resocialización o control social: por un concepto crítico de reintegración social Del condenado. In: ARAÚJO JÚNIOR, João Marcello de. (Org.). Sistema penal para o terceiro milênio: atos do Colóquio Marc Ancel. Rio de Janeiro: Revan, p. 251265, 1991.

Criminologia crítica e crítica do direito penal: introdução à sociologia do direito penal. 2a Ed. Rio de Janeiro: Freitas Bastos, 1999.

BRASIL. Supremo Tribunal Federal. Ministro Presidente Ricardo Lewandowski. ADPF $n$ o 403/PE. Decisão Monocrática datada de 19/07/2016 (DJE no 152, divulgado em 20/07/2016).

BRASIL. Congresso Nacional. Câmara dos Deputados. Comissão Parlamentar de Inquérito do Sistema Carcerário. CPI sistema carcerário 2008. Brasília: Câmara dos Deputados, Edições Câmara, 2009. 
CAVALHEIRO, Patrícia. TJRS usará WhatsApp para fazer intimações. http://www.tjrs.jus.br/site/imprensa/noticias/?idNoticia=330495. Acesso em: 21/07/2016.

CLEMMER, Donald. The prison community. Nova lorque: Holt, Rinehart and Winston, 1966.

COYLE, Andrew. Administração penitenciária: uma abordagem de direitos humanos. Brasília: Ministério da Justiça, 2004.

FEDERAL Bureau of prisons. Disponível em: <http://www.bop.gov/inmate programs/trulincs faq.jsp>. Acesso em: 12 abr. 2017.

GOFFMAN, Erving. Manicômios, prisões e conventos. 4.ed. São Paulo: Perspectiva, 1992.

HASSEMER, Winfried. Introdução aos fundamentos do Direito Penal. Porto Alegre: Sergio Antonio Fabris, 2005.

HM Chief Inspector of Prison. Prison communications inquiry. Londres: 2015. Disponível em $<$ https://www.justiceinspectorates.gov.uk/hmiprisons/wpcontent/uploads/sites/4/2015/07/prison-communications-report-web-2015-2.pdf>.

Acesso em 08 mar. 2017.

LACERDA, Dennis Otte; Pires, João Alberto Simões. Projeto Visita Virtual. Disponível em: <http://www.premioinnovare.com.br/praticas/l/projeto-visita-virtual>. Acesso em: 15 abr. 2017.

LÉVI-STRAUSS, Claude. Tristes trópicos. São Paulo: Companhia das Letras, 1996.

MARCON, João Paulo Falavinha. 0 acesso à internet como um direito humano fundamental, perante as legislações internacional e brasileira. Disponível em: <http://mundorama.net/2013/03/07/o-acesso-a-internet-como-um-direito-humanofundamental-perante-as-legislacoes-internacional-e-brasileira-por-joao-paulo-falavinhamarcon/>. Acesso em: 22 jul. 2016.

MINISTÉRIO DA JUSTIÇA. Departamento Penitenciário Nacional. Penitenciária Federal de Catanduvas-PR. Relatório de pesquisa do perfil sócio-criminal dos internos da Penitenciária Federal de Catanduvas. Disponível em: $<$ http://portal.mi.gov.br/services/DocumentManagement/FileDownload.EZTSvc.asp?Docu mentID=\%7B4C51C4D0\%2D43D9\%2D4DCA\%2D9888\%2D422DCD1F911A\%7D\&Servicelnst UID=\%7BB8AB303A\%2D0639\%2D4154\%2DA9A8\%2D711DA34EE24C\%7D>. Acesso em: 25 set. 2014a.

MINISTÉRIO DA JUSTIÇA. Departamento Penitenciário Nacional. Penitenciária Federal de Campo Grande/MS. Relatório de pesquisa do perfil sócio-criminal dos internos da Penitenciária Federal em Campo Grande/MS. Disponível em: <http://portal.mj.gov.br/services/DocumentManagement/FileDownload.EZTSvc.asp?Docu mentID=\%7B411FC737\%2D06C5\%2D4106\%2DB49E\%2DD68895BF90DB\%7D\&ServicelnstUI $\mathrm{D}=\%$ 7BB8AB303A\%2D0639\%2D4154\%2DA9A8\%2D711DA34EE24C\%7D>. Acesso em: 25 set. 2014b.

MORAES, Pedro Rodolfo Bodê de. Punição, encarceramento e construção de identidade profissional entre agentes penitenciários. São Paulo: IBCCRIM, p. 285, 2005. 
MORETTO, Rodrigo. Crítica interdisciplinar da pena de prisão: controle do espaço na sociedade do tempo. Rio de Janeiro: Lumen Juris, 2005. 161 p.

ONU. Regras mínimas para o tratamento de prisioneiros. Disponibilizado em: <http://www.dhnet.org.br/direitos/sip/onu/fpena/lex52.htm>. Acesso em: 21 jul. 2016.

SANOU, Brahima. The world in 2014: ICT facts and figures. International Telecommunication Union. Disponível em: <http://www.itu.int/en/ITUD/Statistics/Documents/facts/ICTFactsFigures2014-e.pdf>. Acesso em: 21 jul. 2016.

SCHMIDT, Andrei Zenkner. Direitos, deveres e disciplina na execução penal. In: CARVALHO, Salo de (org.). Crítica à Execução Penal. Rio de Janeiro: Lumen Juris, p. 250276, 2007.

THOMPSON, Augusto. A questão penitenciária. 2.ed. Rio de Janeiro.Forense, 1980.

WRITE a prisoner. Disponível em: <http://writeaprisoner.com/>. Acesso em: 12 abr. 2017.

ZAFFARONI, Eugenio Raul. Em busca das penas perdidas: a perda da legitimidade do sistema penal. Rio de Janeiro: Revan, 1991.

RUDNICKI, Dani; VEECK, Matheus Oliveira. Sobre o direito à comunicação e o acesso dos presos à internet. RBSD Revista Brasileira de Sociologia do Direito, v. 5, n. 2, p. 6688, mai./ago. 2018. 